\title{
Poesía y cine: \\ un ensayo sobre la palabra y la imagen
}

\author{
Dr. Víctor Amar \\ Departamento de Didáctica. \\ Universidad de Cádiz
}

\begin{abstract}
RESUMEN
El presente artículo es una reflexión sobre las interrelaciones entre la poesía y el cine, además de la convivencia entre ambas. En este sentido, la presencia de la poesía en el cine se produjo desde, prácticamente, sus orígenes, del mismo modo que el cine aportó el sentido del movimiento a la primera. Con ello, el lector/espectador podría ver en un verso la existencia de un primer plano, del mismo modo que en un plano bien compuesto éste podría llegar a sentir el mejor de los versos de un depurado poema.
\end{abstract}

\section{ABSTRACT}

The present article is a reflection upon them interrelate among the poetry and the movies, besides the contact among both. In this sense, the presence of the poetry in the movies was produced since, practically, its origins, of the same way that the movies contributed the sense of the movement to the first one. With it, the reader/spectator would be able to see in a verse the existence of a first plan, of the same way that in a well composed plan this would be able to come to feel the best of the verses of a purified poem.

Palabras claves: Poesía/Cine/Interrelaciones poesía/cine.

Key words: Poetry/Cinema/Interrelate poem/movies.

«Todo se me confunde cuando creo que recuerdo, es otra cosa la que pienso;

si veo, ignoro, y cuando me distraigo, claramente veo.»

(Fernando Pessoa).

«Puesto que estos misterios me sobrepasan,

fingimos ser sus organizadores.»

(Jean Cocteau). 


\section{A modo de justificación. Para introducir el ensayo}

Sin ánimo de llegar a convertir el presente escrito «Poesía y Cine: Un ensayo sobre la palabra y la imagen» en un texto en el cual se analice concienzudamente los aspectos que poseen en común y, posiblemente, de simbiosis, de influencia... ambas disciplinas artísticas, por ello, hemos optado por reflexionar libremente en torno a éstas, con el propósito de establecer/recuperar la relación mágica existente entre la poesía y el cine. Es decir, la interdisciplinariedad de las artes sea con la poética y la cinematúrgica, así como las competencias comunicativas de ambas.

En este sentido, la manera que hemos optado por compartir nuestras inquietudes sobre estas «sensibilidades» es el ensayo (Skirius, 1981: 9). Sabedores de la imposibilidad de desarrollar un asunto en la totalidad de sus enfoques y tratamientos, hemos centrando nuestra prioridad sobre aquellos aspectos que nos interesan, de forma esencial, y permitiéndonos alguna que otra digresión tangencial; pero siempre con el denominador común de mantener una actitud dialogante, con la clara intencionalidad de no cansar al lector/espectador... El objetivo de la lectura del presente texto es que sea un modo de disfrute, sin soslayar que este tema, ya ha sido tratado por especialistas en ambos procedimientos artísticos por transmitir «emociones» y lo nuestro es, simplemente, una visión particular: un punto de vista más. En cierto modo, un intento por aportar una página más al proceso mágico que funde la poesía con el cine, o viceversa.

«Todo arte y toda poesía tienden esencialmente a suscitar, en el estado de vigilia, un sueño más o menos organizado, una ensoñación en cuya trama se mezclan en variada proporción las dos actividades del espíritu: una de lógica razonadara, otra de encadenamiento sentimental» (Epstain, 1957: 88).

Posiblemente, esta sea la forma que mejor hemos encontrado para invitarles al siempre nutriente ejercicio del debate, a la participación de valores y opiniones que no pretenden ser demostradas, sino simplemente presentadas.

Un modo de cuestionarse un tema delicado, de manera común y cotidiana. Con la clara intención de invitar al lector/espectador al diálogo, recordando al latino Cicerón, en un intento denodado por ganar la benevolencia del auditorio y procurar mantener despierta su atención, su interés.

\section{De la Poesía y el Cine: Parte I.}

Para comenzar a introducirnos el tema y que lo expresado en el ítem anterior es presumiblemente alcanzable, nos valemos como fuente del enunciado a los tópicos relativos al êthos del orador en cuanto a su ética, al pathós con la clara intención de despertar la atención o empatía del lector/espectador. Y, por último, al logos, o bien la organización discursiva de la palabra (Comparato, 1992: 18).

Una vez establecidos estos tres aspectos esenciales, manifestar que tanto el poeta como el cinematurgo responden a las consignas de tramar, narrar y describir 
emociones y pasiones en el lector o en el espectador: la red de receptores.

Los receptores de poesía o cine, en nuestra opinión, suelen mantener una actitud de las menos pasivas ante el ejercicio creativo (antes, durante y después de deleite). Para ellos no es un mero entretenimiento, existen unos planteamientos de disfrute, de análisis, etc., que vienen dados por la capacidad reflexiva, de examen o bien de selección y evocación que posean los potenciales destinatarios de un poema o un film. Inclusive, sería más correcto dirigirse a éstos abarcándoles en un amplio concepto que los estudiosos en la materia han determinado en llamar «narratarios» (Carrière, 1991: 115-125).

En este sentido, escribir una poesía como un guión para cine, es más que escribir. Tal vez, sea escribir con silencios y miradas, con movimientos y pausas que ponen en acción un complejo universo de imágenes y sonidos, que podrían tener un sinnúmero de relaciones entre sí, jugando con las impresiones o el inconsciente, produciendo ambigüedades o concreciones reales, provocando formas invisibles en nuestra imaginación o en nuestras retinas, que rechazamos o abrazamos en plena sintonía. Y ambas maneras de concebir la realidad, o simplemente reinterpretarla, no son el final de un procedimiento literario o cinematográfico, sino más bien el principio de un proceso mágico creativo.

Presentar la belleza por medio de la palabra es un arte antiquísimo y vinculado (hasta la modernidad) con lo sacro-mágico de la cotidianeidad. No obstante, valerse del litterae - imago para manifestar sentimientos y planteamientos estéticos es relativamente reciente, aunque los precedentes cabrían encontrarlos en las culturas antiguas y, sobre todo, en el precine decimonónico. El peso de la palabra impresa coexiste con la palabra transmitida en el medio filmográfico desde, prácticamente, los orígenes del cinematógrafo (a finales del siglo XIX con la particularidad de que, en aquel entonces, más que mudo fue silente). Es decir, en una cinta se incluían desde intertítulos (información de la trama y de los diálogos), hasta componerse e interpretarse una pieza musical en exclusiva para ella, actores y actrices que doblaban a sus referentes en la pantalla, o bien personas entre el público que leían en voz alta los diálogos subtitulados, ante la presencia -en aquel entonces- de espectadores y espectadores que no sabían leer y, con ello, se le facilitaban la comprensión de los diálogos pronunciados en otra lengua.

Lo que en la poesía invita a la imaginación; en el medio audiovisual (cine), ésta no se delimita, sólo y exclusivamente, al marco de la pantalla. Ya que el insinuante fuera de campo también interactúa de manera narrativa, dramática y expresiva, gracias a la capacidad que posee el plano de combinar fuerzas centrífugas y centrípetas, tan sólo con la mirada (Amar, 2000: 145). Así como deberíamos tener presente los recursos concernientes al «audio» como pueden ser la voz en off, screen over, etc., además de su forma de impactar al oído, pues escuchamos los sonidos, silencios, ruidos y palabras (diálogos) que se producen en los 360 
grados que conforman nuestro entorno, mientras vemos en un campo visual muy pequeño y en una sola dirección.

En ambas facetas del arte: la poesía y el cine, la palabra y la imagen, o la combinación de ambas (audiovisual), son los útiles con que se cuentan, sin soslayar los resultados afines o disímiles que pueden producir en los receptores.

Sin embargo, el poeta piensa y transmite los sentimientos a través de las palabras. No obstante, la sensibilidad, observación e imaginación del cineasta se completa con la agudeza visual regida por el espectador. De la inexplicable inspiración del poeta, a aquello que Gustavo Adolfo Bécquer se refirió como: «(...) deformes siluetas / de seres imposibles... Memorias y deseos / de cosas que no existen (...)»; el cinematurgo las metaboliza y las hace proyectar en una sala a oscuras sobre una pantalla blanca y armónica... para que los iconos, por arte de magia, adquieren movimientos, inclusive vida, porque existen, además de hablar porque piensan y actuar porque sienten. La fábrica de sueños comienza a funcionar y el imaginario colectivo empieza a construirse. El talento, la emoción y la empatía, entre otros aspectos, resplandecen como denominador común entre la poesía y el cine.

El poeta sabe que la palabra impresa posee un considerable peso específico. Por ello, debe hurgar en su bagaje cultural para encontrar la palabra que más se adecue rimando, lo mejor posible, a sus sentimientos. El cinematurgo tiene presente el juego de fuerzas que se establece con la palabra transmitida (el cuerpo comunicativo), así como de sus interferencias, del tiempo de atención del público $\mathrm{y}$, a veces, hasta del ulterior doblaje.

A la palabra en cine le resta protagonismo la presencia imperiosa de la imagen; sufre la «distorsión de la dimensión» de la gran pantalla, cautivadora del espectador que acude a la sala de proyección y queda minimizado ante la «tela blanca» (Comparato, 1992: 46).

Los diálogos no son concebidos para ser leídos, sino para ser declamados; además, sería pertinente aunar el concepto «timing»: vocablo anglosajón de difícil traducción al castellano, que cabría entenderlo como llevar el ritmo con la palabra; condición casi imprescindible para agilizar o pausar los diálogos (Chion, 1988: 8792). El cuerpo comunicativo transmite emociones, juega con los sentimientos, construye, reconstruye y deconstruye. En definitiva, es arte.

\section{Del Cine y la Poesía: Parte II.}

Cine y poesía son dos manifestaciones artísticas, dos experiencias estéticas que provocan en el espectador y en el lector el goce que produce la contemplación comprensiva o la evocación, inclusive elevándola a la categoría de lo sublime. En este sentido, coincidimos con J. Pijoán (1980, vol. 1: 3), autor de la inefable 
Summa artis, cuando apunta que «la creación y apreciación de la belleza es una experiencia puramente humana. El hombre podría definirse como el animal que tiene capacidad estética».

La experiencia estética se vitaliza ante un film o una poesía. Las emociones que podemos experimentar cerrando los ojos en el momento en que escuchamos recitar unos versos resultarían un símil, si cabe, igual a las impresiones que registramos cuando abrimos los ojos en una sala de proyección a oscuras y a nuestras espaldas un haz de luz da vida a unas sombras en movimientos sobre un lienzo blanco. Estamos ante un proceso de hipnosis propio del sentido estético (Ferrés, 1996: 24-26). Un gesto que reafirma la razón observadora.

Para los receptores reflexivos resulta ser un merecido ejercicio de reencuentro con la belleza (Quintana Cabanas, 1993). Ésta, que viene dada por el icono en movimiento o bien por la palabra (escrita o la voz), los receptores la captan, la decodifican, la metabolizan... y completan el proceso de la comunicación, aumentando en él la impresión estética y, por tanto, su capacidad para el disfrute con el arte - cine y poesía - a partir de la propia experiencia cotidiana (intelectiva, discursiva y expresiva).

Ambas experiencias artísticas centran la percepción del placer en la estimulación de los sentidos; a partir del deleite que produce el contemplarla o el oírla. Atendiendo a los aspectos objetivos (si está en los iconos o en las palabras) y subjetivos (a raíz de la propia recreación personal motivada por la imagen o la palabra), que de forma individual o conjunta de ellas se desprenden, pudiendo llegar a poner de relieve que una de sus finalidades es la empatía.

El punto y seguido lo estableceríamos a partir de la afirmación de Federic Schiller (1990: 26), quien indicó que la «belleza es aquella forma que no exige ninguna explicación». Y, tal vez, ninguna explicación precisa añadir que la plurisignificación o ambigüedad, logicidad o ilogicidad, además de su asintactismo y metaforicidad (Ortega y Gasset, 1983)... son partes propias del lenguaje cinematográfico y poético por excelencia, produciendo en los receptores el deseado deleite estético.

Frente a ello, la fealdad, aquello que K. Rosenkranz (1992) distinguió como un objeto diferente al que identificamos como bello. En cierta manera, cabría apuntar que todas las cosas participan de la belleza y de la fealdad, es una cuestión personal, de una comunidad, de un período de la historia, de una cultura, de una situación, de una moda, así como de la educación y de la experiencia estética que se tenga.

El ejercicio propuesto, en lo concerniente al cine y la poesía, o viceversa, se resumiría en que un film o un poema no sólo hay que oírlo o contemplarlo con los sentidos de la vista o del oído. Sería pertinente y hasta aconsejable, para establecer y lograr aquello que denominamos deleite, valiéndonos de la imaginación, que se potenciara el sentir imaginativo. Sugiriendo, y comunicando a la vez, 
una suntuosa actividad de recreación artística provocando y prolongando la imaginación -o reacción- de los receptores.

Cine y poesía son dos artes que se corresponden y, en sí, se complementan. De igual manera, valdría decir que un lector/espectador podría ver en un verso casi un primer plano o un primerísimo primer plano -poniendo de relieve la microfisonomía-, así como en un plano bien compuesto el mejor de los versos de un depurado poema. Ambas maneras artísticas y comunicativas hacen que la vida sea más intensa, inclusive llegándose a un estado de hechizo e hipnosis, motivado por lo intenso, la sugestión, la armonía, la belleza, la posición privilegiada de sentir el arte que en el caso de la poesía viene incrementado por lo sublime, lo poético. $\mathrm{Y}$, a propósito del cine, está estimulado por la oscuridad que rige el espectáculo audiovisual, así como de la fuerza innata y cautivadora del icono, además del montaje (Gubern, 1994: 318).

Sendas artes - cinematúrgica y poética - juegan un papel relevante en la vida cotidiana, sensible y mágica, cercana a la acción terapéutica de las mismas, ya que la evocación, recurso inherente a ambas -igualmente, extensibles a otras artes-, pueden estimular lo beneficioso de la existencia, el aprecio a las personas y el afecto hacia todo lo que nos rodea: aprender sintiendo y sentir aprendiendo.

La evocación establecerá un papel protagónico en el proceso de la contemplación artística de un film o un poema. Es la supremacía de la voluntad positiva frente a la perversidad que adormece la capacidad del encantamiento, del disfrute, etc. Sin querer soslayar la capacidad de ilusión, atendiendo a las diversas acepciones que cada uno de nosotros quisiera otorgarle, desde el inductor al mero «arte por el arte», pasando por la satisfacción personal, el simple disfrute emocional, o bien como un medio educativo y de concienciación de masas de orientación marxista o neomarxista (Linares, 1976: 15).

A la postre, el resultado es una ecuación que cuenta como denominador común con la sensibilidad y la imaginación, mezcla de lo innato y lo adquirido: un producto cultural y social. Eugenio D'Ors (s.a.: 17) realizó el siguiente comentario: «El ver no resulta tan fácil negocio como la gente se imagina; que también el saber ver exige una disciplina propedéutica rigurosa. No es comprender sin ver, pero tampoco se alcanza visión sin comprensión».

Ambas formas - cine y poesía - son maneras expresivas, creativas, además de vehículos creadores/transmisores de belleza, de categoría artística, de valor/ mérito y de calidad estética. Por tanto, considerémoslas obras de artes repletas de intencionalidad, creatividad, invención, funcionalidad, artificialidad... e, inclusive, sentimientos. Nos encontramos ante dos artes expresivas y emotivas, además de creativas: original y estética. Cine y poesía mantienen, por consiguiente, una relación pluridisciplinar y interdisciplinar. Tal vez, nos encontremos frente a una nueva definición y clasificación artística, además de una actitud 
y experiencia estética aunque, eso sí, sin olvidar que se tratan de medios, lenguajes y procedimientos expresivos... diferentes, no divergentes. El cine no puede olvidar el sistema de producción y el concepto teckné (tecnología), mientras que la poesía cuenta con la inspiración del autor. Sin embargo, un aspecto que las aglutina bien podría ser el de la mágica sensación que produce la aparente verosimilitud (en la retina con el cine y la imaginada en el caso de la poesía).

Sendas artes explican el universo cultural; suponen un proceso cargado de significación, expresión y comunicación que se elaboran a partir de criterios que han de ser decodificados por los receptores, suponiendo un ejercicio intelectual y un estímulo social y cultural (Metz, 1971). Del mismo modo que explican y hacen más inteligible al hombre y a la mujer, su tiempo y espacio, así como su contexto y su complicada naturaleza (entre la razón y los sentimientos). En definitiva, ambas expresiones estéticas suponen un esfuerzo entusiasta para encontrar aquellas referencias al ser humano que quedan por entender.

\section{A modo de epílogo. Para concluir el ensayo}

Pese a las diferencias entre ambas artes, establecidas a partir de sus medios, (literario y audiovisual), que adoptan una determinación bastante singular a raíz del valor de la palabra transmitida, la representación y del reforzamiento que ésta adquiere. Al respecto de la palabra en el cine, en un principio, simbolizada con significado propio (escritura) en su período silente y, a partir del advenimiento del sonoro, con la inclusión de la palabra declamada, ésta conformó parte del metraje. En este sentido, la «métrica» y el «espectáculo ocular» no deberían entenderse como dos formas artísticas independientes, cabría considerarlas como complementarias.

La poesía y el cine, quizás, tengan más elementos en común que los aglutina que, propiamente, los separa. El poeta y el cineasta caminan llevado de la mano de la inspiración, así como de algo tan importante y, a la vez, olvidado como es el oficio.

Dos expresiones artísticas, creativas, con la finalidad, inmediata, de expresar la belleza por medio del lenguaje. En el caso de la poesía (del griego poiesis) a través de la lengua escrita. Y, en relación con, el medio filmográfico/audiovisual gracias al lenguaje cinematográfico (del griego kineto -> movimiento y grafo -> imagen). Dos formas de producción de emociones y de comunicar, a la vez que sostienen una depurada estructura estética, imaginativa y afectiva sobre quién las leyera, escuchara o viera.

Coincidencias o divergencias con respecto a la capacidad expresiva y sensitiva de estas dos singulares aportaciones a la comunicación social (McQuail, 2000), en la cual se desenvuelven, destacar que ambas producen deleite. Sin 
olvidar la propia concepción y evolución particular, así como las estructuras internas e impulsos, el ritmo distinto y las experiencias que despiertan/registran en el narratario o en el espectador diversas emociones... En definitiva, la poesía y el cine conmueven.

La poesía y el cine, o viceversa, son ritmo y montaje; fragmentación y velocidad; vitalidad y exaltación espectacular; metáfora/tragedia y estética de la sensualidad; armonía y sensibilidad. Es decir, verso y planificación... O lo que manifestó el cineasta polaco-francés Jean Epstein (1957: 74): «(...). Por ser profundamente instintivo, sentimental y emotivo, el pensamiento visual es apropiado en grado sumo para la función poética y, en la mayoría de las mentalidades, esta correspondencia es insustituible. Por eso, el film, más que ningún otro modo de expresión, se manifiesta constitucionalmente organizado para servir de vehículo a la poesía».

Dos maneras instantáneas de condensar el tiempo, de sentir el arte, de dialogar, de tener presente dos formas artificiosas de presentar la vida, que se contagian. Como escribió Fernando Vela (1927: 27), «El cine apenas pide nada para la memoria. La imagen poética, por ejemplo, se realiza en la cabeza del lector mediante una recordación. El arte del cine no permite tan dulces remembranzas. Es un poco bárbaro».

En este ensayo hemos pretendido presentar algunos aspectos de la poesía y el cine; del poeta y del cinematurgo. Somos conscientes de que ha habido películas inspiradas en poemas, en vidas de poetas, escritas en versos, con un tratamiento (de forma y de contenido) poético. O bien, poetas que han quedado fascinados por el cine y la filmografía (por ejemplo, el poeta portuense Rafael Alberti...), que han escrito basándose en la magia del cine... o, simplemente, han llevado una «vida de película». En fin, este escrito que determinamos en titular «Poesía y Cine: un ensayo sobre la palabra y la imagen» ha sido un gesto creativo, con el propósito de esbozarles más problemas que de resolverles planteamientos de cualquier índole sobre estas dos disciplinas, a propósito de estas dos experiencias estéticas.

«Si te hablo con parábolas es para que lo entiendas mejor. No se puede definir el horror y sin embargo existe, porque avanza en silencio.» De este singular modo, se expresaba el instructor al pequeño Alejandro en la película $O$ megalexandros (1970) del cineasta griego Theo Angelopoulos, un poeta de la imagen. Un maestro de la poesía visual, de invitarnos a sentir y disfrutar con la representatividad de la poesía hecha imágenes.

Poesía y cine, o viceversa, son maneras como otras cualesquiera de imaginar, de transformar la realidad. De, por ejemplo, explicar el imaginario, y hasta de depurar la realidad. Un ejercicio comparativo pretencioso e inductor que funciona en el subconsciente de los receptores por analogía, con unos resultados rayanos de 
belleza e intensidad expresiva. El resultado que obtenemos es lo más cercano a un efecto de simulación.

Igualmente, no estaría de más finalizarlo reproduciendo unas líneas del clásico Aristóteles, quien en su obra titulada La retórica, todo un referente clásico, apuntó: «cuando se acuña un término, éste debe denotar una especie real y una diferencia específica; si no, lo que se consigue es pura palabrería vacía y frívola».

\section{Referencias:}

- AMAR, V. (2000): "La alfabetización audiovisual a través de la educación con el cine", Comunicar, 15; 141-148.

- CARRIÉRE, J-C. (1991): Práctica del guión cinematográfico. Barcelona, Paidós.

- CHION, M. (1988): Cómo se escribe un guión. Madrid, Cátedra.

- Comparato, D. (1992): De la idea al guión. Madrid, IORTV.

- D’ORS, E. (s.a.): Tres lecciones en el Museo del Prado de introducción a la crítica del arte. Madrid, Ediciones Españolas.

- EPSTAIN, J. (1957): La esencia del cine. Buenos Aires, Galatea Nueva Visión.

- FERRÉS, J. (1996): Televisión y educación. Barcelona, Paidós.

- GUBERN, R. (1994): La mirada opulenta. Exploración de la iconosfera contemporánea. Barcelona, Gustavo Gili.

- LINARES, A. (1976): El cine militante. Madrid, Castellote.

- MCQUAIL, D. (2000): Introducción a la teoría de la comunicación de masas. Barcelona, Paidós.

- METZ, C. (1971): Langage et cinéma. París. Larousse.

- ORTEGA Y GASSET, J. (1983): La deshumanización del arte. Vol 3. Madrid, Alianza.

- PIJOÁN, J. (1980): Summa Artis. Historia general del arte. Madrid, Espasa Calpe.

- QUINTANA CABANAS, J.A. (1993): Pedagogía estética. Madrid, Dykinson.

- ROSENKRANZ, K. (1992): Estética de lo feo. Madrid, Julio Ollero.

- SCHILLER, F. (1990): Kallias. Cartas sobre la educación estética del hombre. Barcelona, Anthropos.

- SKIRIUS, J. (1981): El ensayo hipanoamericano del siglo XX. México, Fondo de Cultura Económico.

- VELA, F. (1927): "El arte al cubo y otros ensayos", en Cuadernos literarios, $27 ; 25-34$. 